\title{
Superior Technology of Lung Cancer Surgery: Robotic Surgery
}

\author{
Anil Gokce ${ }^{1 *}$ and Celal Bugra Sezen ${ }^{2}$ \\ ${ }^{1}$ Department of Thoracic Surgery, University of Health Sciences, Ankara City Hospital, Turkey \\ ${ }^{2}$ Department of Thoracic Surgery, University of Health Sciences, Yedikule Chest Diseases and Thoracic Surgery \\ Training and Research Hospital, Turkey
}

\begin{abstract}
With the effect of the developing technology in thoracic surgery, it has been possible to treat lung resections with robotic surgery in recent years. Many articles have supported Minimally Invasive Surgery (MIS) against the traditional open approach. Both Video-Assisted Thoracic Surgery (VATS) and Robot-Assisted Thoracic Surgery (RATS) have shown better perioperative results and equivalent oncological results compared to thoracotomy. Compared to VATS, robotic thoracic surgery provides easier operations in the lung cancer, the robot has better instruments and better view of the field of operation; 3 -dimensional instead of 2-dimensional; $\times 10$ magnification instead of $\times 2$ or $\times 3$; and less fogging, thus less camera manipulation. Robotic thoracic surgery is considered the next step in the evolution of minimally invasive surgery, since the robot allows a more complex and precise operation than VATS. This article reviews worldwide experience of robotic thoracic surgery and discusses potential benefits and limitations of using the robotic platform to perform thoracic surgery procedures.
\end{abstract}

Keywords: Non-small cell lung cancer; Robotic surgery; Minimal invasive surgery

\section{Introduction}

Robotic thoracic surgery is the newest evolution of minimally invasive surgery for non-small cell lung cancer, and minimally invasive surgery allows for meticulous dissection of large anatomical structures while balancing the morbidity of painful thoracic incisions. This benefit means better results and recovery following surgical management of lung resections. With development of surgical techniques and devices, advanced Non-Small Cell Lung Cancer (NSCLC) patients are treated with MIS, including video-assisted thoracoscopic surgery and robotic-assisted thoracic. Preliminary reports on robotic thoracic surgery show that a robotic approach has some advantages compared to a video-assisted technique. These include easier operations in the mediastinum, such as thymectomy or resection of the esophageal leiomyoma, robot has better instruments and a better view of the field of operation; 3-dimensional instead of 2-dimensional; $\times 10$ magnification instead of $\times 2$ or $\times 3$; and less fogging, thus less camera manipulation. Most surgeons who try to learn both Video-Assisted Thoracic Surgery (VATS) and robotic techniques agree that robot provides advantages for mediastinal and esophageal operations. These advantages for lung surgery include better dissection of enlarged or metastatic N1 lymph nodes from pulmonary artery, more precise and comprehensive $\mathrm{N} 2$ lymph node dissection, and less operative blood loss. In addition, operative technique of robotic lobectomy mimics open surgery more closely than VATS technique [1]. In this study, systematic examinations were carried out to perform NSCLC operations using robotic surgery technique by PubMed database. By analyzing data of many studies, current advantages and disadvantages of robotic surgery are also revealed in comparative results with other surgical methods. As a result of this study, it has been aimed to shed light on thoracic surgeons in terms of optimum use of robotic surgery method, which has been used rapidly in recent years.

2945

Copyright $\odot 2020$ Anil Gokce. This is an open access article distributed under the Creative Commons Attribution License, which permits unrestricted use, distribution, and reproduction in any medium, provided the original work is properly cited.

\section{Robotic Thoracic Surgery - Da Vinci}

Implementation of the Da Vinci surgical system has helped overcome certain VATS limitations, such as Three-Dimensional (3D) vision and counter-intuitive movement using long rigid instruments that allow thoracic surgeons to perform multiple minimally invasive thoracic procedures more efficiently. This system has 3 flexible instruments and a stereoscopic binocular camera, all of which are contained in a cannula with a diameter of $2.5 \mathrm{~cm}$. Unlike the previous robotic single-plant platform, this system has flexible instruments; therefore, it can be used for complex 


\begin{tabular}{|c|c|c|c|c|c|c|c|c|c|}
\hline References & Year & $\begin{array}{l}\text { Number } \\
\text { of } \\
\text { Patients }\end{array}$ & Stage & $\begin{array}{l}\text { Resected M edian Lymph Nodes and } \\
\text { Lymph Nodes Stations }\end{array}$ & $\begin{array}{c}\text { Conversions } \\
\text { to } \\
\text { Thoracotomy } \\
(\%)\end{array}$ & $\begin{array}{l}\text { Median } \\
\text { Times of } \\
\text { Operation } \\
\text { (minutes) }\end{array}$ & $\begin{array}{l}\text { Times of } \\
\text { Stay in } \\
\text { Hospital } \\
\text { (days) }\end{array}$ & $\begin{array}{c}\text { Postoperative } \\
30 \text { Days } \\
\text { Morbidity } \\
(\%)\end{array}$ & $\begin{array}{l}\text { Postoperative } \\
30 \text { Days } \\
\text { Mortality } \\
(\%)\end{array}$ \\
\hline Cerfolio RJ. et al. ${ }^{2}$ & 2018 & 1339 & 672 IA, 281 IB, $118\|\mathrm{I}, 99\| \mathrm{II}, 143|||\mathrm{A}, 8||| \mathrm{B}, 18 \mathrm{IV}$ & Lymph Nodes: 13 & 9 & 136 & 3 & 8 & 0,2 \\
\hline Liang $\mathrm{H}$. et al. ${ }^{3}$ & 2018 & 3239 & - & $\begin{array}{c}\text { Lymph Nodes: } 11.96 \\
\text { Lymph Nodes Stations: } 4.978\end{array}$ & 10.3 & 176.63 & 4.9 & 27.5 & 0.7 \\
\hline Casiraghi M. et al. ${ }^{5}$ & 2019 & 339 & $264|A, 54| B, 17|| A, 4|| B$ & $\begin{array}{l}\text { Lymph Nodes: N1: } 9 \mathrm{~N} 2: 6 \\
\text { Lymph Nodes Stations: N1: } 2 \text { N2: } 3\end{array}$ & 6.5 & 191 & 5 & 2.4 & 0 \\
\hline Wilson JL. et al. ${ }^{10}$ & 2014 & 302 & $200 \mathrm{IA}, 1021 \mathrm{~B}$ & 20.9 & - & - & 3.4 & 10.6 & 0 \\
\hline LiC. etal. ${ }^{7}$ & 2019 & 36 & $16\|B, 20\| A$ & Lymph Nodes: N1:13 & 2.7 & - & 4 & 13.9 & 0 \\
\hline Toosi K. et al. ${ }^{9}$ & 2016 & 249 & $117|\mathrm{~A}, 42| \mathrm{B}, 20\|\mathrm{~A}, 11\| \mathrm{\| B}, 44\|\mathrm{II}, 3\| \mathrm{IIB}, 12 \mathrm{IV}$ & $\begin{array}{c}\text { Lymph Nodes: N1+N2 } 13.9 \pm 0.4 \\
\text { Lymph Nodes Stations: } 1+\mathrm{N} 2 \\
5.5 .9 \pm 0.4\end{array}$ & 3.2 & 178 & 5 & 7.2 & 2.4 \\
\hline Lee BE. et al. ${ }^{4}$ & 2015 & 53 & . & Lymph Nodes: 17 & $\cdot$ & 161 & 3 & 11 & 0 \\
\hline Y ang HX. et al. ${ }^{6}$ & 2017 & 172 & $139 \mathrm{IA}, 33 \mathrm{IB}$ & Lymph Nodes Stations:5 & 9.3 & - & 4 & - & 0 \\
\hline Zirafa CC. et al. ${ }^{8}$ & 2019 & 212 & $80|A, 68| \mathrm{IB}, 20\|\mathrm{~A}, 17\| \mathrm{B}, 23\|\mathrm{I}, 1\| \mathrm{A}, 3 \mid \mathrm{I}$ & - & 3.8 & 215 & 3.6 & 18.3 & 5.2 \\
\hline
\end{tabular}

procedures in thoracic surgery. However, there are some limitations in the application of the Da Vinci SP system in thoracic surgery. First, robotic single-port cannula makes it difficult to pass the cannula 2.5 $\mathrm{cm}$ in diameter through the intercostal spaces. In addition, the SP system needs a length of more than $10 \mathrm{~cm}$ between the cannula tip and the lesion to triangulate instruments and ensure complete joint joints of both elbow and wrist instruments. Partial articulation of the wrist joint is possible with an insertion length of about $5 \mathrm{~cm}$.

\section{Robotic Lung Resections}

Minimally invasive thoracic surgery developed in time, process which started with use of first thoracoscope in the early 1900s, has progressed rapidly in complex procedures such as lobectomy, pneumonectomy, esophagectomy and resection of mediastinal tumors. Video-assisted thoracic surgery offered great benefits compared to thoracotomy with less postoperative pain and narcotic use, shorter intensive care unit and hospital stay, faster return to work and better cosmetic appearance. Implementing Da Vinci surgical system with advancing technology, Three-Dimensional (3D) vision and thoracic surgeons have adopted a closer technique to open surgery, providing a better field of view, overcoming various VATS limitations, allowing for more minimally invasive thoracic procedures to be performed more efficiently Table 1 . Now a day, robotic technology has started to be used in many medical centers and they have started to present data of large series of cases together. In the study of Cerfolio [1] it was stated that 1,339 patients who underwent by robot-assisted thoracic surgery, the median operation time was $136 \mathrm{~min}$, median lymph node number, median blood loss was $50 \mathrm{cc}$, and 4 patients underwent intraoperative transfusion. 116 patients had conversion to thoracotomy, 24 patients had bleeding, median duration of stay was 3 days, and major morbidity was observed in $8 \%$ of patients. 30-day and 90-day operative mortality was $0.2 \%$ and $0.5 \%$, respectively. It was observed that results were significantly better than the surgery performed with thoracotomy, and it was shown to have better results than video-assisted surgery in terms of features such as average blood loss amount and return to thoracotomy [2]. Videoassisted thoracic surgery is used as a standard method in many centers, with the advent and application of robotic technology, its use in lung resections has increased. When we look at the literature, there are various studies comparing video assisted surgery with robotic surgery. In the study of Liang [3] it was stated that 3,239 patients underwent Robotic-Assisted Lobectomy/Segmentectomy (RAL/S), while other 4,199 patients underwent Video-Assisted Lobectomy/Segmentectomy (VAL/S). 30 days mortality rate was $0.7 \%$ vs. $1.1 \%$ and conversion rate to open surgery was $10.3 \%$ vs. $11.9 \%$, respectively. Postoperative complications were significantly lower for RAL/S than VAL/S, hospitalization time was 4.90 in robotic surgery and 5.23 days in video-assisted surgery, the duration of the chest tube stay was 4.10 days in robotic surgery and 3.53 days in video-assisted surgery. It was reported that the number of lymph nodes and lymph node stations removed were similar in two groups. In this current meta-analysis, RAL/S confirmed that it was a viable and safe alternative to $\mathrm{VAL} / \mathrm{S}$ for radical resection of lung cancer, and future studies should focus on the long-term benefits and costeffectiveness of RAL/S compared to VAL/S. In a comparative study in terms of another oncological principles of Lee BE [4] it was reported that 211 patients underwent anatomical lobectomy with VATS ( $n=158)$ or robotics $(n=53)$, which was statistically similar in the clinical stages, tumor sizes, locations and histological evaluations of the 2 groups. In the VATS group, 24 patients had nodal upstaging, 13 patients had $\mathrm{pN} 1$ disease and 11 patients had $\mathrm{pN} 2$ disease, the robotic group had nodal upstaging, 7 patients, 5 patients had pN1 disease and 2 patients had $\mathrm{pN} 2$ disease. When VATS and robotics were compared, there was no significant difference in the pathological upper stage, 2 -year overall survival was $88 \%$ vs. $95 \%$; 2 -year disease-free survival was $83 \%$ vs. $93 \%$ respectively. In this comparison of robotic and VATS lobectomy for clinical lymph node negative lung cancer, managed by consistent surgical technique and pathological evaluation, nodal upstaging rate obtained with robotics appeared to be similar to VATS, and there was no significant difference in diseasefree or overall survival. According to these results, robotic surgery has results consistent with the literature in comparison with video assisted surgery in terms of general features and oncological principles. In the early years of minimally invasive surgery, video-assisted surgical features were used in early-stage lung cancer patients, since there were several drawbacks in terms of oncolic principles. And in the studies conducted over time, there were no drawbacks in terms of providing oncological principles. It has been used in robotic surgery especially in early stage lung cancer patients and various publications have started to appear in the literature over time. In the study of 


\begin{tabular}{|c|c|c|c|c|c|c|}
\hline References & Y ear & $\begin{array}{l}\text { Number } \\
\text { of } \\
\text { Patients }\end{array}$ & Stage & $\begin{array}{c}\text { Follow-up } \\
\text { Time } \\
\text { (months) }\end{array}$ & $\begin{array}{c}\text { Survival } \\
\text { Times }\end{array}$ & $\begin{array}{l}\text { Overall Survival } \\
\text { (\% or months) }\end{array}$ \\
\hline Cerfolio RJ . et al. ${ }^{2}$ & 2018 & 1339 & $672|A, 281| \mathrm{B}, 118\|\mathrm{~A}, 99\| \mathrm{I}, 143\|\mathrm{~A}, 8\| \| \mathrm{B}, 18 \mid \mathrm{V}$ & 30 & 5 -year & $77 \%$ \\
\hline Liang H. et al. ${ }^{3}$ & 2018 & 3239 & - & 45 & $5-Y$ ear & $83 \%$ \\
\hline Casiraghi M . et al. ${ }^{5}$ & 2019 & 339 & $264|A, 54| B, 17\|A, 4\| B$ & 28.8 & $\begin{array}{l}\text { 2-year } \\
5 \text {-year }\end{array}$ & $\begin{array}{l}96.1 \% \\
91.5 \%\end{array}$ \\
\hline Wilson J L. et al. ${ }^{10}$ & 2014 & 302 & Stage I & 12.3 & 2 -year & $87.6 \%$ \\
\hline Li C. et al. ${ }^{7}$ & 2019 & 36 & $16\|\mathrm{~B}, 20\| \mathrm{A}$ & 33.9 & 3-year & $75.7 \%$ \\
\hline Toosi K. et al. ${ }^{9}$ & 2016 & 249 & $117 \mathrm{IA}, 42 \mathrm{IB}, 20\|\mathrm{I}, 11 \mathrm{IIB}, 44\| \mathrm{II}, 3 \mathrm{IIIB}, 12 \mathrm{IV}$ & 18 & $\begin{array}{l}\text { 1-year } \\
\text { 3-year }\end{array}$ & $\begin{array}{l}91 \% \text { and } 70 \% \text { for stage I } \\
80 \% \text { and } 64 \% \text { for stage II II } \\
78 \% \text { and } 57 \% \text { for stage III } \\
71 \% \text { and } 45 \% \text { for stage IV }\end{array}$ \\
\hline Lee BE. et al. ${ }^{4}$ & 2015 & 53 & - & 13.3 & 2 -year & $95 \%$ \\
\hline $\mathrm{Y}$ ang $\mathrm{HX}$. et al. ${ }^{6}$ & 2017 & 172 & $139|A, 33| B$ & 39.8 & 5-year & $77.6 \%$ \\
\hline Zirafa CC. et al. ${ }^{8}$ & 2019 & 212 & $80|\mathrm{~A}, 68| \mathrm{B}, 20\|\mathrm{~A}, 17\| \mathrm{B}, 23\|\mathrm{~A}, 1\| \mathrm{\| B}, 3 \mathrm{IV}$ & 40.3 & M onths & $\begin{array}{l}\text { Overall: } 78.6 \text { months } \\
82 \text { months for stage I } \\
73.5 \text { months for stage II } \\
61.4 \text { months for stage III } \\
41.3 \text { months for stage IV }\end{array}$ \\
\hline
\end{tabular}

Casiraghi [5] it was reported that 339 patients who underwent RATS due to clinical stage I $(n=318)$ and II $(n=21)$ NSCLC were reviewed, 29 patients underwent segmentectomy, 307 lobectomy and 3 pneumonectomy. The mean operation time was $192 \mathrm{~min}$ for lobectomy, $172 \mathrm{~min}$ for segmentectomy and $275 \mathrm{~min}$ for pneumonectomy, and the average hospital stay was 5 days. The most common complication after surgery was prolonged air leakage, major complications occur in 8 patients, 30-day and 90-day operative mortality was $0 \%$ and $0.3 \%, 2$ and 5 -year survival rates are $96.1 \%$ and $91.5 \%$, respectively. Early lung cancer patients were examined in the study of Yang [6] it was reported that 470 clinical stage I NSCLC patients operated: 172 robotics, 141 VATS and 157 open, the robotic approach collected more lymph node stations: 5 stations robotics, 3 stations VATS and 4 stations thoracotomy. Patients with minimally invasive approaches had shorter hospital stays: 4 days for robotics, 4 days for VATS, 5 days for open. 5-year overall survival for robotic, VATS and open-matched groups was $77.6 \%, 73.5 \%$ and $77.9 \%$, respectively, without a statistically significant difference. 5-year disease-free survival was reported as $72.7 \%, 65.5 \%$ and $69.0 \%$, respectively, with a statistically significant difference between robotics and VATS. Minimally invasive approaches to lobectomy for clinical stage I NSCLC have resulted in long-term survival similar to thoracotomy, significantly less hospital stay and complications in VATS and robotic surgery, and it has been emphasized that robotic surgery has significantly better results in lymph node dissection. Robotic surgery, which has similar survival results in terms of oncological principles; it is thought to be superior to other methods with less complications, less hospital stay, and less pain. Robotic surgery was started in advanced lung cancer patients as the series of cases in the early stages increased, the oncological results were compatible with the literature data and the number of experienced centers increased. In the study of Li [7] it was stated that the clinical stage IIB-IIIA NSCLC 121 patients, 36 robot lobectomy and 85 VATS lobectomy, were examined, and no perioperative death was observed in both groups. It was stated that postoperative morbidity was similar as $13.9 \%$ for RATS and $15.3 \%$ for VATS. Patients who underwent robotic lobectomy had a shorter stay in hospital for 4 days and the number of resected lymph nodes was higher. The mean disease-free survival for the RATS and VATS groups was 31.1 and 33.8 months, respectively, 3-year disease-free survival was $40.3 \%$ in the RATS group and $47.6 \%$ in the VATS group, 3-year overall survival was $75.7 \%$ in RATS and $77.0 \%$ in the VATS group. In other study, advanced cases were evaluated by Zirafa [8] it was stated 212 patients who underwent robotic surgery were analyzed, the mean follow-up time was 40.3 months, median disease-free survival was 66.3 months, disease-free survival was associated with stage and 75.6 months for stage I, 42.3 months for II, 51.2 months for stage III and 10.3 months for stage IV, and the median survival was 78.6 months. It was stated that overall survival was 82 months for stage I, 73.5 months for stage II, 61.4 months for stage III and 41.3 months for stage IV. It was emphasized that in advanced stage NSCLC patients, robotic lobectomy was safe and effective with a low complication rate and similar long-term results compared to VATS lobectomy, and that the robotic approach results in shorter postoperative stay time and more lymph node evaluation. In lung cancer surgery, lymph node positivity is one of basic factors in the staging of patient Table 2. For this reason, regardless of surgical method performed, complete dissection of appropriate lymph node stations is very important due to tumor localization. In preoperative evaluation, nodal upstaging may be seen in the pathological staging performed after operation in patients who do not consider lymph node involvement, and especially full evaluation of nodal micrometastases becomes very important. In one of the studies conducted on this subject, Toosi [9] reported that 249 patients who underwent robot-assisted lobectomy for non-small cell lung cancer were examined, the number of median mediastinal lymph nodes removed was 7.7, 159 patients were clinical stage I, 134 patients were pathological stage I. It was stated that 67 patients were nodal upstaging: 20 patients were $\mathrm{cN} 0$ to $\mathrm{pN} 1,17$ patients were $\mathrm{cN} 0$ to $\mathrm{pN} 2,4$ patients were $\mathrm{cN} 1$ to $\mathrm{pN} 2$, and 37 patients were nodal downstaging. 1 and 3-year survival rates were $91 \%$ and $70 \%$ for clinical stage I, $80 \%$ and $64 \%$ for clinical stage II, $78 \%$ and $57 \%$ for clinical stage III, $71 \%$ and $45 \%$ for clinical stage IV, $92 \%$ and $75 \%$ for pathological stage I, $83 \%$ and $73 \%$ for pathological stage II, $75 \%$ and $44 \%$ for pathological stage III, $67 \%$ and $0 \%$ for pathological stage IV, respectively. In the study of Wilson [10] it was stated that patients with clinical stage I NSCLC after robotic lobectomy or segmentectomy were analyzed, 302 patients underwent robotic anatomical lung resection, most were clinical stage IA, and 33 patients had pathological 
nodal upstaging. Increased hilar (pN1) was reported to occur for cT1a, cT1b and cT2a tumors as $3.5 \%, 8.6 \%$ and $10.8 \%$, respectively. Compared to other surgical methods, it was observed that there are similar results with the literature data. In the light of these and similar studies, it was emphasized that robotic assisted resections contributed to the adequate evaluation of mediastinal lymph node dissection lymph node stations and detection of hidden lymph node metastasis. With the increasing technology and accessibility to robotic systems over time, there is an increase in the number of centers performing robotic lung surgery. In one of studies to guide robotic surgery centers, Cheufou [11] reported that robotic lobectomy was performed in 64 patients, the indications, preoperative lung functions, comorbidities, patient age and tumor stage were similar between patients during and after the learning curve, and the median operation time, the amount of complications seen, and the length of hospital stay could be significantly reduced after the learning curve.

\section{Conclusion}

Video-Assisted Thoracic Surgery (VATS) is a minimally invasive approach for resectable lung cancer, with several advantages according to thoracotomy. However, use of VATS is limited mainly due to rigid tools and limited visibility. Robot technology seems to have overcome these limitations. Retrospective studies show that robot-assisted thoracic surgery is feasible and safe. Limited long-term results show oncological results similar to open and VATS approaches. Robotic approach facilitates surgery with more intuitive movements, greater flexibility and high definition, three-dimensional vision. However, high cost and lack of touch sense are main disadvantages of robotic surgery. Considering technological developments until now, it may be predicted that next generation robots will have sense of touch in the near future. For this reason, the biggest problem of robotic surgery may be considered as cost. Some works on how cost of robotic surgery may be reduced continue. Even if cost per case is reduced, considering installation cost, annual maintenance cost and robotic arm costs of robotic system, it is thought that cost-effectiveness problem will continue for a while. However, with spread of new generation robots and competition in different manufacturers, it is thought that costs of robotic surgery may be reduced in the future.

\section{Acknowledgment}

Anil Gokce would like to thank Prof. Robert J. Cerfolio for the chance to work together about robotic thoracic surgery in New York University Langone Health Center and the contributions to this article.

\section{References}

1. Cerfolio RJ. Pulmonary resection in the $21^{\text {st }}$ century the role of robotics. Tex Heart Inst J. 2012;39(6):848-9.

2. Cerfolio RJ, Ghanim AF, Dylewski M, Veronesi G, Spaggiari L, Park BJ. The long-term survival of robotic lobectomy for non-small cell lung cancer: A multi-institutional study. J Thorac Cardiovasc Surg. 2018;155(2):778-86.

3. Liang H, Liang W, Zhao L, Chen D, Zhang J, Zhang Y, et al. Robotic versus Video-Assisted Lobectomy/Segmentectomy for lung cancer: A meta analysis. Ann Surg. 2018;268:254-9.

4. Lee BE, Shapiro M, Rutledge JR, Korst RJ. Nodal upstaging in robotic and video assisted thoracic surgery lobectomy for clinical N0 lung cancer. Ann Thorac Surg. 2015;100(1):229-34.

5. Casiraghi M, Galetta D, Borri A, Tessitore A, Romano R, Diotti C, et al. Ten years' experience in robotic-assisted thoracic surgery for early stage lung cancer. Thorac Cardiovasc Surg. 2019;67(7):564-72.

6. Yang HX, Woo KM, Sima CS, Bains MS, Adusumilli PS, Huang J, et al. Long-term survival based on the surgical approach to lobectomy for clinical stage I nonsmall cell lung cancer: Comparison of robotic, video-assisted thoracic surgery, and thoracotomy lobectomy. Ann Surg. 2017;265(2):431-7.

7. Li C, Hu Y, Huang J, Li J, Jiang L, Lin H, et al. Comparison of roboticassisted lobectomy with video-assisted thoracic surgery for stage IIB-IIIA non-small cell lung cancer. Transl Lung Cancer Res. 2019;8(6):820-8.

8. Zirafa CC, Cavaliere I, Ricciardi S, Romano G, Davini F, Aprile V, et al. Long-term oncologic results for robotic major lung resection in NonSmall Cell Lung Cancer (NSCLC) patients. Surg Oncol. 2019;28:223-7.

9. Toosi K, Velez-Cubian FO, Glover J, Ng EP, Moodie CC, Garrett JR, et al. Upstaging and survival after robotic-assisted thoracoscopic lobectomy for non-small cell lung cancer. Surgery. 2016;160:1211-8.

10. Wilson JL, Louie BE, Cerfolio RJ, Park BJ, Vallières E, Aye RW, et al. The prevalence of nodal upstaging during robotic lung resection in early stage non-small cell lung cancer. Ann Thora Surgery. 2014;97:1901-7.

11. Cheufou DH, Mardanzai K, Ploenes T, Theegarten D, Stamatis G, Kampe $\mathrm{S}$, et al. Effectiveness of robotic lobectomy-outcome and learning curve in a high volume center. Thorac Cardiovasc Surg. 2019;67:573-7. 